\title{
ВЛИЯНИЕ НОРМЫ ВЫСЕВА НА УРОЖАЙНОСТЬ РАПСА В СЕВЕРО-КАЗАХСТАНСКОЙ ОБЛАСТИ
}

\author{
E.A. Cherkasova, V.V. Rzaeva
}

\section{THE INFLUENCE OF SEEDING RATE ON RAPES YIELD IN THE NORTH-KAZAKHSTAN REGION}

Черкасова Е.A. - асп. каф. земледелия Государственного аграрного университета Северного Зауралья, г. Тюмень, преп. Высшего сельскохозяйственного колледжа им. Жалела Кизатова, Республика Казахстан, Северо-Казахстанская обл., Есильский р-н, с. Покровка.

E-mail: evgeniyacherkasova92@mail.ru

Рзаева В.В. - канд. с.-х. наук, доц., зав. каф. земледелия Государственного аграрного университета Северного Зауралья, г. Тюмень.

E-mail: valentina.rzaeva@yandex.ru

Цель исследований - выявление оптимальной нормы высева сортов и гибридов ярового рапса на семена в условиях Северного Казахстана. Задачи: для определения оптимальной нормы высева семян провести оценку элементов структуры урожая и биологической урожайности масла семян, рассмотреть метеоданные за вегетационный период и провести анализ экспериментального материала с учетом обеспеченности растений влагой и теплом. Предметом исследования выступают сорта и гибриды ярового рапса. На экспериментальных полях Есильского государственного зернокормового сортоиспытательного участка, находящегося в Республике Казахстан (село Явленка Есильского района СевероКазахстанской области), в 2019 году было проведено конкурсное испьтание ярового рапса, представленного 5 сортами (Юбилейный (стандарт) Герос, Майкудык, Хантер, Махаон) и 3 гибридами (Калибр, Билдер, GEN0009). Изучение сортов и гибридов проведено на фоне предшественника - чистый пар, по нескольким нормам высева, а именно 2; 2,5 и 3 млн всхожих семян. Основные учеты и наблюдения проводили согласно утвержденной методике государственного сортоиспытания. Проведенные исследования позволили установить, что семенная продуктивность растений рапса нахо-
Cherkasova E.A. - Post-Graduate Student, Chair of Agriculture, Northern Trans-Urals State Agrarian University, Tyumen, Lecturer, Higher Agricultural College named after Zhalel Kizatov, the Republic of Kazakhstan, North Kazakhstan Region, Esilsky District, V. Pokrovka.

E-mail: evgeniyacherkasova92@mail.ru

Rzaeva V.V. - Cand. Agr. Sci., Assoc. Prof., Chair of Agriculture, Northern Trans-Urals State Agrarian University, Tyumen.

E-mail: valentina.rzaeva@yandex.ru

дится в тесной взаимосвязи с метеорологическими условиями вегетационного периода и изучаемых вариантов опыта. В результате исследований норм высева пришли к выводу, что наибольшую продуктивность обеспечиваem panc с нормой высева 2,0 млн и 2,5 млн всхожих семян, а с увеличением нормы высева урожайность снижается, в частности сорт Майкудык при норме высева 2 млн всхожих семян имеет биологическую урожайность 29,2 щ/2а, наименьшую биологическую урожайность имеет гибрид Билдер - 17,3 и/га при норме высева 3 млн всхожих семян.

Ключевые слова: яровой рапс, норма высева, гибрид, сорт, сортоиспытание, урожайHOCmb.

The research objective was to determine optimal seeding rate of varieties and hybrids of spring rape for seeds in the conditions of Northern Kazakhstan. The objectives were to determine optimal seeding rate to assess the elements of the structure of the crop and biological yield of oilseeds, to consider meteorological data for growing season and to analyze experimental material, taking into account the provision of plants with moisture and heat. The subjects of the research were varieties and hybrids of spring rape. On experimental fields of the Yesil State Grain and Feed Varietal Testing 
Site located in the Republic of Kazakhstan, North Kazakhstan Region, Esil District, the village of Yavlenka in 2019, a competitive test of spring rape was carried out, represented by 5 varieties: Geros, Maykudyk, Hunter, Machaon and 3 hybrids: Caliber, Bilder, GEN0009. The study of varieties and hybrids was carried out against the background of the predecessor - bare fallow, according to several seeding norms, namely 2, 2.5 and $3 \mathrm{~m} / \mathrm{n}$ germinating seeds. The main accounts and observations were carried out according to approved methodology of the state variety testing. Performed researches allowed to establish that seed productivity of rape plants was in close dependence from meteorological conditions of vegetative period and studied variants of experiment As a result of the researches of the norms of seeding the conclusion was made that the highest productivity provided canola with a seeding rate of $2.0 \mathrm{mln}$ and $2.5 \mathrm{mln}$ of germinating seeds, but with the increase in seeding rate, the yield was reduced, in particular variety had Maykudyk at seeding rate of $2 \mathrm{mln}$ viable seeds had biological yield of $29.2 \mathrm{~kg} / \mathrm{hectare}$, the lowest biological productivity had the hybrid Bilder $17.3 \mathrm{c} /$ hectare at a sowing rate of $3 \mathrm{mln}$ germinating seeds.

Keywords: spring rape, seeding rate, hybrid, variety, variety testing, productivity.

Введение. В современных условиях развития отрасли растениеводства на сегодняшний день выбор оптимальной нормы высева ярового рапса, как и любой другой сельскохозяйственной культуры, является важным элементом технологии возделывания, так как сильно загущенные и, наоборот, изреженные посевы являются неэфффективными. Рапс является достаточно требовательной культурой к условиям возделывания [1, 2], а установление оптимальной нормы высева - одно из определяющих условий для получения высокой урожайности ярового рапса.

За последние несколько десятилетий изменились многие позиции в технологии возделывания ярового рапса: с каждым годом появляются новшества в технологии посева и ухода за посевами, появились новые пестициды, а также изменился и сортовой состав [3, 4]. А значит, помимо определения оптимальной нормы высева, одной из основных предпосылок получения высоких и, что особенно важно, стабильных урожаев ярового рапса является правильный выбор сорта. В связи с этим перед государством и сортоиспытательными участками стоит задача подобрать для каждой почвенноклиматической зоны лучшие сорта рапса не только отечественной, но и зарубежной селекции, которые в полной мере отвечают тем требованиям, которые диктует производство. Так как при диверсификации сельскохозяйственного производства внедрение перспективных сортов и гибридов актуально и экономически эффективно [5].

Цель исследований. Выявление оптимальной нормы высева сортов и гибридов ярового рапса на семена в условиях Северного Казахстана.

Задачи исследований: провести оценку элементов структуры урожая и биологической урожайности маслосемян для определения оптимальной нормы высева семян; рассмотреть метеоданые за вегетационный период и провести анализ экспериментального материала с учетом обеспеченности растений влагой и теплом.

Методы. Основные учеты и наблюдения проводили согласно утвержденной методике государственного сортоиспытания [6]. Статистическая обработка экспериментальных данных проведена методом дисперсионного анализа [7]. Структура урожая определяется по снопам, взятым с площадок размером 0,25 м² (по 4 на каждой делянке), по всем вариантам.

Урожайность с приведением ее к стандартной влажности определяют по следующей формуле: $\mathrm{X}=(\mathrm{Y} \cdot(100-\mathrm{B})) / 100-\mathrm{C}_{\mathrm{B}}$, где $\mathrm{X}$ - окончательная урожайность $C$ приведением к стандартной влажности, ц/га; У - урожайность при уборке, ц/га; В - влажность зерна, \%; Св - стандартная влажность для данной культуры, \%.

На экспериментальных полях Есильского государственного зернокормового сортоиспытательного участка было проведено конкурсное испытание ярового рапса, представленного восемью образцами, из них 5 сортов: Юбилейный (стандарт), Герос (Германия), Майкудык (Казахстан), Хантер (Германия), Махаон (Казахстан) и 3 гибрида: Калибр (Германия), Билдер (Германия), GEN0009 (Казахстан).

Опыт закладывался по типу питомника конкурсного сортоиспытания, площадь учетной де-

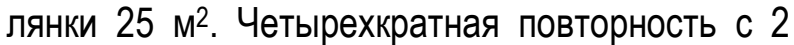


ярусами в опыте. Варианты размещены рендомизированно. Изучали несколько норм высева, а именно 2; 2,5 и 3 млн всхожих семян на га.

Предшественник - чистый пар. Сельскохозяйственные работы при проведении опыта следующие: 02.09.2018 г. проведена зяблевая обработка почвы на глубину 20-22 см КПГ-5 + МТЗ 1221. Весной при наступлении физической спелости почвы проведено боронование на глубину 5-6 см ЗИГЗАГ, предпосевная обработка почвы с одно-временным внесением удобрения (аммофос, доза 25-30 кг/га) - СЗС 2,1, агрегатируемая трактором МТ3 1221. Посев ярового рапса произведен селекционной сеялкой «Winter-steiger» 21 мая, междурядье $15 \mathrm{~cm}$. Глубина заделки семян - 3 см. Через 3-4 суток после посева - боронование до всходов бороной БЗСС-1,0 с целью уничтожения сорняков. Опрыскивание посевов гербицидом Нопасаран (0,8 л/га) проведено в фазу 2-6 листьев культуры. В течение вегетации для борьбы с комплексом вредителей (крестоцветная блошка, рапсовый цветоед, капустная белянка и др.) осуществлялась 2-кратная обработка систем-ными инсектицидами Биская (0,3 л/га) и Децис Профи (0,03 л/га). Уборка проведена селекционным комбайном «Винтерштайгер».

Результаты исследований и их обсуждение. Среднесуточная температура за апрель 2019 г. составила $5{ }^{\circ} \mathrm{C}$ при норме $3,4{ }^{\circ} \mathrm{C}$. Количество осадков, выпавших за месяц, 22,6 мм при норме 21,0 мм. Среднесуточная температура за май составила $13^{\circ} \mathrm{C}$, что в пределах нормы. Количество осадков, выпавших за месяц, - 11,7 мм при норме 31,0 мм. Среднесуточная температура за июнь составила $+16{ }^{\circ} \mathrm{C}$, что соответствует среднемноголетним показателям. Количество осадков, выпавших за месяц, составило 22,2 мм (норма 38-49 мм). Среднесуточная температура за июль на $1,5^{\circ} \mathrm{C}$ превышала среднемноголетние параметры $\left(22^{\circ} \mathrm{C}\right)$.
Количество осадков, выпавших за месяц, составило 75,1 мм ( норма 53-72 мм).

В целом за анализируемый период среднесуточная температура в основном соответствовала климатической норме, но в мае и июне отмечен существенный дефицит влаги, что повлияло на рост и развитие культуры. Проведенные исследования позволили установить, что семенная продуктивность растений рапса находится в тесной взаимосвязи с метеорологическими условиями вегетацион-ного периода и изучаемых вариантов опыта.

Исследованиями было доказано, что урожайность рапса ярового имела прямую связь с числом плодов на растении, а также числом семян в плоде, а число плодов на растении уменьшалось с увеличением густоты стояния растений (табл.). Также стоит отметить, что урожайность рапса ярового формировалась главным образом за счет количественных признаков числа плодов на растении и числа семян в плоде, алогичные результаты отмечены в работах [8-11].

С нормой высева 2 млн и 2,5 млн всхожих семян максимальное число стручков на растении сформировал сорт Майкудык - 40,8 и 39,3 шт/раст соответственно, что превысило показатель контроля (сорт Юбилейный при норме высева 2 млн всхожих семян 37,1 шт/раст и при норме высева 2,5 млн всхожих семян - 36,7 шт/раст) на 3,7 и 2,6 шт/раст, разница составляет $9 \%$ при норме высева 2 млн всхожих семян и 6,6 \% при норме высева 2,5 млн всхожих семян. При норме высева 3 млн всхожих семян максимальное количество стручков сформировал гибрид Калибр, данный показатель составил 37,2 шт/раст, что превысило контроль на $8 \%$ (сорт Юбилейный - 34,2 шт/раст). Стоит заметить, что в загущенных посевах из-за конкуренции растения ветвятся слабее, образуют меньшее количество стручков и семян, которые имеют небольшие размеры, в результате чего продуктивность рапса снижается. 
Элементы структуры урожая, биологическая урожайность сортов и гибридов ярового рапса за 2019 год

\begin{tabular}{|c|c|c|c|c|c|c|c|c|c|c|c|c|}
\hline \multirow[b]{3}{*}{$\begin{array}{l}\text { Сорт, } \\
\text { гибрид }\end{array}$} & \multicolumn{12}{|c|}{ Норма высева рапса } \\
\hline & \multicolumn{4}{|c|}{2 млн всхожих семян } & \multicolumn{4}{|c|}{ 2,5 млн всхожих семян } & \multicolumn{4}{|c|}{3 млн всхожих семян } \\
\hline & 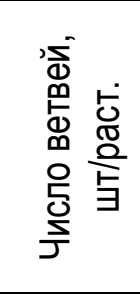 & 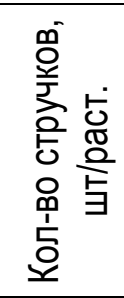 & 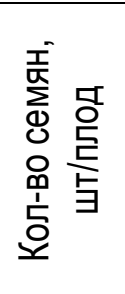 & 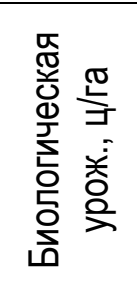 & 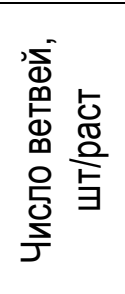 & 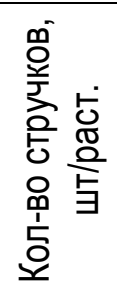 & 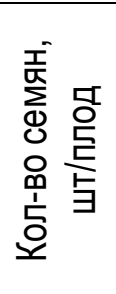 & 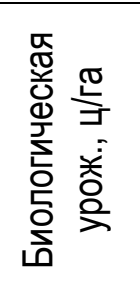 & 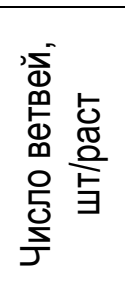 & 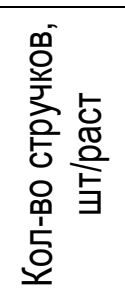 & 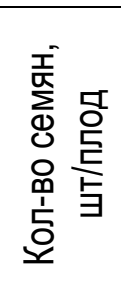 & 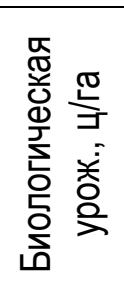 \\
\hline Юбилейный st. & 3,6 & 37,1 & 15,8 & 21,1 & 3,6 & 36,7 & 15,8 & 25,1 & 3,5 & 34,2 & 15,1 & 20,8 \\
\hline Герос & 3,5 & 38,2 & 16,8 & 19,7 & 3,5 & 39,1 & 16,8 & 26,1 & 3,4 & 36,1 & 15,5 & 17,7 \\
\hline Майкудык & 3,7 & 40,8 & 17,1 & 29,2 & 3,6 & 39,3 & 17,1 & 26,6 & 3,5 & 36,3 & 16,3 & 25,9 \\
\hline Хантер & 3,6 & 38,4 & 17,5 & 25,0 & 3,5 & 37,7 & 17,5 & 24,8 & 3,4 & 33,9 & 16,1 & 20,6 \\
\hline МaxaOH & 3,5 & 37,7 & 16,7 & 22,1 & 3,6 & 38,3 & 16,7 & 23,0 & 3,6 & 35,7 & 15,7 & 18,1 \\
\hline Калибр & 3,8 & 38,7 & 15,9 & 22,9 & 3,4 & 38,1 & 15,9 & 21,8 & 3,2 & 37,2 & 14,1 & 18,7 \\
\hline Билдер & 3,6 & 39,3 & 16,2 & 22,1 & 3,5 & 38,8 & 16,2 & 20,6 & 3,3 & 36,1 & 15,1 & 17,3 \\
\hline GEN0009 & 3,7 & 36,8 & 16,5 & 20,4 & 3,4 & 37,2 & 16,5 & 23,4 & 3,4 & 34,3 & 15,4 & 19,1 \\
\hline $\mathrm{HCP}_{05}$ & \multicolumn{4}{|r|}{3,04} & \multicolumn{4}{|r|}{2,09} & \multicolumn{4}{|r|}{2,77} \\
\hline
\end{tabular}


Выводы. Оптимальное соотношение между количеством растений на единицу площади, числом стручков, семян в стручке формируется при норме высева от 2,0 млн до 2,5 млн всхожих семян на 1 га. На основании анализа структуры урожая были выделены наиболее урожайные сорта рапса, которые превышали сортстандарт на $8 \%$ и более. К ним отнесены сорта: Майкудык (29,2 ц/га), Хантер (25,0 ц/га), Герос $(26,1$ ц/га) и гибрид Калибр (22,9 ц/га). Урожайность сорта Юбилейный (стандарт) составила 21,1 ц/га при норме высева 2 млн всхожих семян и 25,1 ц/га при норме высева 2,5 млн всхожих семян.

Проанализировав полученный материал по результатам исследований за 2019 год, стоит отметить тот факт, что яровой рапс при повышенных нормах высева (учитывая внушительную вегетативную массу растений вследствие большой густоты стояния) формирует меньше ветвей на растении, а также меньшее количество семян в стручке.

Результаты исследований оптимальной нормы высева показали, что наибольшую продуктивность обеспечивает яровой рапс с нормой высева 2,0 млн и 2,5 млн всхожих семян, с увеличением нормы высева урожайность снижается, в частности 29,2 ц/га имеет урожайность сорт Майкудык при норме высева 2 млн всхожих семян, а наименьшей урожайностью выделился гибрид Билдер, его урожайность составила 17,3 ц/га при норме высева 3 млн всхожих семян.

\section{Литература}

1. Олейникова Е.Н., Янова М.А., Пьжикова Н.И. [и др.]. Яровой рапс - перспективная культура для развития агропромышленного комплекса Красноярского края // Вестник КрасГАУ. - 2019. - № 1. - С. 74-80.

2. Аветисян A.T., Данилова В.В., Данилов H.B. [и др.]. Технология возделывания кормовых культур в Красноярском крае. Красноярск, 2012. - 150 с.

3. Бопn В.Л., Пьжикова Н.И., Кураченко Н.Л. [и др.]. Обоснование способов и сроков уборки масличных культур (рапс, рыжик, горчица) в условиях Канской лесостепи // Вестник КрасГАУ. - 2019. - № 6. - С. 52-58.
4. Лобова Т.В., Субботина М.A. Рапс - перспективная культура Сибири // Новая наука: опыт, традиции, инновации. - 2016. - № 9. - C. 82-84.

5. Кашеваров Н.И., Нурльгаянов Р.Б., Ахметгареев Р.Ф. Развитие производства ярового рапса в Западной Сибири. - Кемерово, 2015. - $185 \mathrm{c}$

6. Методика ГСИ сельскохозяйственных культур / отв. ред. М.А. Федина. - М.: Колос, 1985. - 267 C.

7. Доспехов Б.А. Методика полевого опыта. М.: Колос, 1979. - $416 \mathrm{c.}$

8. Лобова Т.В., Субботина М.A. Рапс - перспективная культура Сибири // Новая наука: опыт, традиции, инновации: мат-лы междунар. науч.-практ. конфр. (12 сентября 2016 г., г. Омск). - Стерлитамак: АМИ, 2016. C. 82-84.

9. Асташина С.И., Асташин И.М. Изучение продуктивности и качественных показателей сортов и гибридов ярового рапса // Научное обеспечение инновационного развития агропромышленного комплекса регионов РФ: мат-лы междунар. науч.-практ. конф. - Новосибирск, 2018. - С. 482-487.

10. Абуова А.Б. Подбор сортов ярового рапса в условиях Северного Казахстана // Известия Нижневолжского агроуниверситетского комплекса. Наука и высшее профессиональное образование. - 2012. - № 2. - С. 55-59.

11. Гольиман С.В., Рендов Н.А., Горбачева Т.В. Экономическая эфффективность интенсификации технологии возделывания ярового рапса на маслосемена в южной лесостепи Западной Сибири // Вестник КрасГАУ. 2007. - № 6. - С. 27-31.

\section{Literatura}

1. Olejnikova E.N., Janova M.A., Pyzhikova N.I. [i dr.]. Jarovoj raps - perspektivnaja kul'tura dlja razvitija agropromyshlennogo kompleksa Krasnojarskogo kraja // Vestnik KrasGAU. 2019. - № 1. - S. 74-80.

2. Avetisjan A.T., Danilova V.V., Danilov N.V. [i dr.]. Tehnologija vozdelyvanija kormovyh kul'tur v Krasnojarskom krae. - Krasnojarsk, 2012. - $150 \mathrm{~s}$. 
3. Bopp V.L., Pyzhikova N.I., Kurachenko N.L. [i dr.]. Obosnovanie sposobov i srokov uborki maslichnyh kul'tur (raps, ryzhik, gorchica) v uslovijah Kanskoj lesostepi // Vestnik KrasGAU. - 2019. - № 6. - S. 52-58.

4. Lobova T.V., Subbotina M.A. Raps perspektivnaja kul'tura Sibiri // Novaja nauka: opyt, tradicii, innovacii. - 2016. - № 9. S. 82-84.

5. Kashevarov N.I., Nurlygajanov R.B., Ahmetgareev R.F. Razvitie proizvodstva jarovogo rapsa $v$ Zapadnoj Sibiri. - Kemerovo, 2015. - $185 \mathrm{~s}$

6. Metodika GSI sel'skohozjajstvennyh kul'tur / otv. red. M.A. Fedina. - M.: Kolos, 1985. - 267 s.

7. Dospehov B.A. Metodika polevogo opyta. M.: Kolos, 1979. - $416 \mathrm{~s}$.

8. Lobova T.V., Subbotina M.A. Raps perspektivnaja kul'tura Sibiri // Novaja nauka: opyt, tradicii, innovacii: mat-ly mezhdunar. nauch.-prakt. konf. (12 sentjabrja 2016 g., g. Omsk). - Sterlitamak: AMI, 2016. S. 82-84.

9. Astashina S.I., Astashin I.M. Izuchenie produktivnosti i kachestvennyh pokazatelej sortov i gibridov jarovogo rapsa // Nauchnoe obespechenie innovacionnogo razvitija agropromyshlennogo kompleksa regionov RF: mat-ly mezhdunar. nauch.-prakt. konf. - Novosibirsk, 2018. - S. 482-487.

10. Abuova A.B. Podbor sortov jarovogo rapsa v uslovijah Severnogo Kazahstana // Izvestija Nizhnevolzhskogo agrouniversitetskogo kompleksa. Nauka i vysshee professional'noe obrazovanie. - 2012. - № 2. - S. 55-59.

11. Gol'cman S.V., Rendov N.A., Gorbacheva T.V. Jekonomicheskaja jeffektivnost' intensifikacii tehnologii vozdelyvanija jarovogo rapsa na maslosemena $\mathrm{v}$ juzhnoj lesostepi Zapadnoj Sibiri // Vestnik KrasGAU. - 2007. - № 6. S. 27-31. 